\title{
LOS ÁNGELES NO SUEÑAN
}

\section{Fernando Mora Zahonero}

Recibido: 30/01/2020. Aceptado: 23/02/2020.

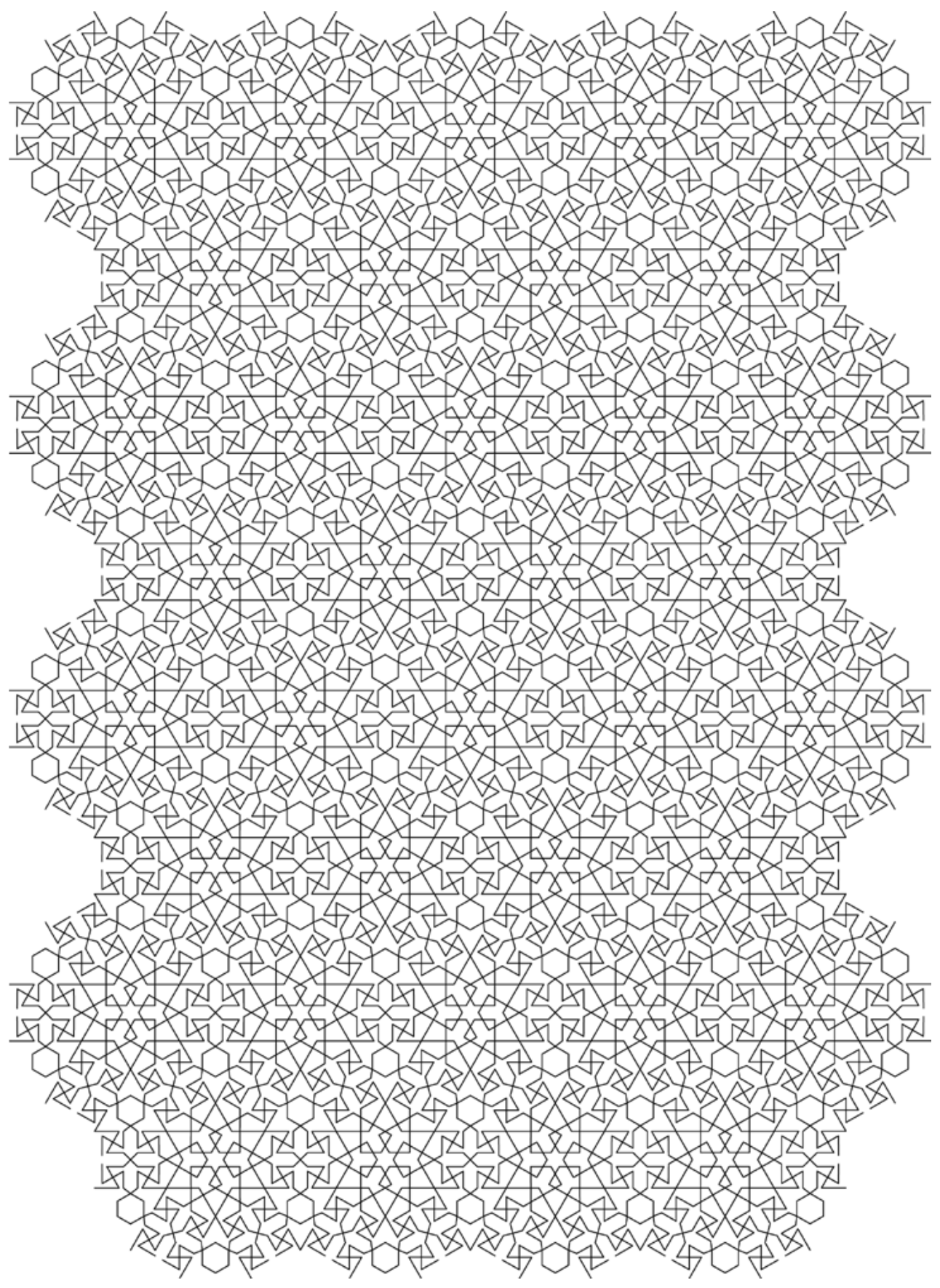


Resumen: Ante un mundo «desangelado» como es el nuestro, cobran especial importancia las visiones no sólo espirituales, como puedan ser el cristianismo o el islam, sino también psicológicas, como la psicología junguiana, que tratan de restituir la sacralidad del mundo a su justo lugar. Tanto Ibn 'Arabī como Sohravardī son grandes exponentes tradicionales de la dimensión angelical de la existencia, siguiendo los lineamientos instaurados por el Corán de que la creencia en los ángeles constituye un principio irrenunciable de la fe musulmana. El ángel es el mensajero de lo invisible o «hermeneuta del silencio divino». No sólo es portador de la palabra divina, como en el caso de Gabriel anunciándose a María o revelando el Corán a Muhammad, sino que la misma palabra es un ángel que se hace carne cuando hablamos, lo cual entronca de pleno con la ciencia de las letras ('ilm al-hurūf), propia del sufismo, donde cada letra es considerada un ángel. El idioma de los ángeles también es sinónimo del célebre y misterioso «lenguaje de los pájaros», dominado por el profeta Salomón. Este idioma original, este lenguaje de los pájaros, es el que permite, según la tradición bíblica, que Adán asigne nombre a cada cosa y también el que lo lleva a entablar un fructífero diálogo con todo lo que le rodea, ya sea mineral, vegetal o animal. La nostalgia del Edén -escribe el poeta José Ángel Valente- es el deseo de reconstruir ese lenguaje primigenio en la situación de no-dualidad del paraíso, en el que las palabras eran cosas y las cosas palabras. Existen, según el islam, distintas categorías de ángeles, cumpliendo diferentes funciones, desde la Revelación, hasta cuidar de la lluvia, las plantas y otros seres y regir los movimientos planetarios o el desarrollo del feto, etcétera. A pesar de lo anterior, Ibn 'Arabī también nos dice que el ser humano perfecto (al-insān al-kāmil) tiene una posición preponderante sobre los ángeles, puesto que es acreedor de todos los nombres divinos, tanto los de rigor como los de misericordia, mientras que los ángeles tienen un predominio limitado sobre estos nombres. Es por eso que Dios ordena a los ángeles que se postren ante esa criatura paradójica y magnífica que es el ser humano primordial, quien a diferencia de ellos es un ser completo que puede mostrar una aproximación más integral a la naturaleza de la realidad.

Palabras clave: Ángel, palabra, ciencia de las letras, sufismo, Corán, lenguaje de los pájaros, funciones angélicas, ser humano perfecto. 
Abstract: In the face of a "dispirited" world such as ours, visions that are not only spiritual, such as Christianity or Islam, but also psychological, such as Jungian psychology, which seek to restore the sacredness of the world to its rightful place, take on special importance. Ibn 'Arabī and Sohravardī are both great traditional exponents of the angelic dimension of existence, following the guidelines established by the Koran that belief in angels constitutes an inalienable principle of the Muslim faith. The angel is the messenger of the invisible or "hermeneutist of the divine silence". Not only is he the bearer of the divine word, as in the case of Gabriel announcing himself to Mary or revealing the Koran to Muhammad, but the word itself is an angel that becomes flesh when we speak, which is fully connected with the science of letters ( $\{l m$ al-hurüf), typical of Sufism, where each letter is considered an angel. The language of the angels is also synonymous with the famous and mysterious "language of the birds", dominated by the prophet Solomon. This original language, this language of the birds, is the one that allows, according to the biblical tradition, Adam to assign a name to each thing and also the one that leads him to enter into a fruitful dialogue with everything that surrounds him, whether mineral, vegetable or animal. "Nostalgia for Eden", writes the poet José Ángel Valente, "is the desire to reconstruct that primeval language in the non-dual situation of paradise, in which words were things and things were words." There are, according to Islam, different categories of angels, fulfilling different functions, from Revelation, to caring for rain, plants and other beings and governing planetary movements or the development of the foetus, and so on. In spite of the above, Ibn 'Arabì also tells us that the perfect human being (al-insān al-kämil) has a preponderant position over angels, since he is worthy of all divine names, both those of Rigour and those of Mercy, while angels have a limited predominance over these names. That is why God commands the angels to prostrate themselves before that paradoxical and magnificent creature that is primordial man, who, unlike them, is a complete being who can show a more comprehensive approach to the nature of reality.

Key words: Angel, word, science of letters, Sufism, Koran, language of birds, angelic functions, perfect human being. 
Teniendo presente que, en una sociedad como la nuestra - gravemente aquejada por los afanes del materialismo- no es fácil hablar de determinadas cuestiones, y siendo conscientes también de que son muchos los consumidores compulsivos, con o sin educación universitaria, que adquieren de manera indiscriminada todo tipo de productos en el floreciente supermercado espiritual -como cultos sectarios, rituales «cuánticos», esoterismo desaforado, sanaciones milagrosas, etcétera-, a lo largo de las páginas siguientes atravesaremos una verdadera tierra de nadie ubicada entre los dogmas propios de la fe ciega y los variados artículos que se ofertan en el mentado supermercado de la Nueva Era; entre el territorio de los credos sostenidos de manera irracional y el imperio de un mundo, como el actual, hace mucho desangelado; entre las discusiones bizantinas en torno, por ejemplo, al número de ángeles que caben en la cabeza de una aguja y la necesidad de reconocer que su presencia -y la de otros seres sutiles hoy en día considerados fantásticos- tiene mucho que ver, como han demostrado ampliamente exponentes de la psicología profunda, como Carl G. Jung y James Hillman, con nuestra plenitud psicológica.

A propósito de una sociedad en la que no sólo los ángeles, sino otros vestigios de misterio y profundidad, se han visto despojados de cualquier carta de naturaleza, y en la que imperan las fuerzas de la concreción, la limitación y el egoísmo, parecen más indicadas que nunca las palabras del gran sabio persa Sohravardī en las que señala que los ángeles son una cofradía de seres inmateriales, procedentes del país del no-donde. ${ }^{1}$ Este país remoto, a la par que próximo, no es sino lo que, en la cosmología de Ibn 'Arabī y de otros ilustres exponentes del sufismo, se conoce como el mundo intermedio de la imaginación activa, ubicado entre la dimensión del puro espíritu y el plano material ordinario, el lugar sin lugar en el que, según la conocida formulación de Henry Corbin, se espiritualizan los cuerpos y adquieren cuerpo los espíritus. Es este plano intermedio de existencia, que fluctúa entre el mundo tenebroso y denso de los cuerpos materiales y el plano luminoso y sutil de las entidades espirituales, un territorio fronterizo donde entran en contacto seres pertenecientes a órdenes distintos de la realidad y en el que se dan cita ángeles, genios y seres humanos que han vivido en distintas épocas o que se hallan a miles de kilómetros de distancia del sujeto que accede a dicho ámbito de conciencia. Es en esta dimensión intermedia donde se desarrolla, el «drama central de la existencia humana». ${ }^{2}$

Se nos antoja imperativo -tanto personal como colectivamente- recuperar esa dimensión sutil que nos conecta con lo que está más allá de nuestros sentidos ordinarios, dado que, como hemos apuntado, vivimos en una cultura que prima lo visible y confía tan sólo en

1 Sihaboddin Yahya Sohravardi, El encuentro con el ángel: Tres relatos visionarios comentados y anotados por Henri Corbin. Madrid, Editorial Trotta, 2002, pp. 74-75.

2 Miguel Cruz Hernández, Historia del pensamiento en el mundo islámico. Tomo I: Desde los orígenes hasta el S.XII. Madrid, Alianza editorial, 1981, p. 288. 
aquello que puede tocarse, mensurarse y cuantificarse, sin darnos cuenta de que la vida depende de muchas cosas que trascienden el alcance de nuestros aparatos de medición, y que, al potenciar un único aspecto de la existencia, estamos mutilando nuestra totalidad, convirtiéndonos en lisiados espirituales. Así pues, si la sociedad actual nos conmina a tomar en consideración solamente aquello que podemos ver y palpar, la visión espiritual del mundo nos aconseja creer en aquello que no puede ser visto ni aprehendido, y no sólo eso, sino que además declara que se trata de la faceta más decisiva de la existencia. El Corán, por ejemplo, se refiere a la creencia en lo invisible como uno de los signos que permiten reconocer a los verdaderos musulmanes. Lo visible hunde sus raíces en lo invisible, de igual modo que la palabra brota del silencio e, inexorablemente, retorna a él.

El antropólogo y mitólogo francés Gilbert Durand señala que el ángel es imagen «de la función simbólica misma que es mediadora entre la trascendencia del significado y el mundo manifiesto de los signos concretos, encarnados, que por medio de ella se transforman en símbolos». ${ }^{3}$ El mismo Durand recuerda la concepción que sobre este particular mantiene el citado Henry Corbin, quien señala que el ángel nos pone en contacto con las diferentes gradaciones simbólicas del ser y que, en él, se halla contenido tanto lo particular como lo general, poniendo ambos términos en relación. A este respecto, menciona el propio Corbin que «La idea de "Ángel” es la de una individualidad que es en sí misma su especie»*4

Creer en los ángeles (en árabe, malä̉ika; sing. malak / malāk) es uno de los seis artículos de fe islámica, además de la fe en Allāh, los enviados, las escrituras (tanto la revelada a Muhammad como las precedentes, es decir, la Torá y los Evangelios) y el Día del Juicio. Es por ello que cuando el Libro revelado pide a los musulmanes que tengan fe, esa petición se refiere a todos y cada uno de los elementos recién enumerados, una fórmula que con ligeras variaciones se repite tres veces en el Corán (2:177, 2:285, 4:136), así como en distintos hadices. La relación con el mundo angélico tal vez sea en el seno del islam (al menos desde que Occidente se vio privado de esta dimensión a partir del Renacimiento) un imperativo más apremiante que en otras tradiciones religiosas, hasta el punto de que no se entendería el islam sin la presencia de los ángeles, los cuales forman parte intrínseca de la revelación coránica, dado que esta llegó hasta el Profeta por intermediación del arcángel Ğibrīl (Gabriel), de quien nos asegura el Corán que es uno de los «próximos» (muqarrabūn). Por ello, rechazar la existencia de los ángeles equivale a negar la revelación coránica. Esa es la razón de que, ateniéndose a una lógica temporal, se los mencione en el texto sagrado antes que a los enviados y las escrituras.

3 Gilbert Durand, La imaginación simbólica. Madrid, Amorrortu, 2007, p. 32.

4 Henry Corbin, El hombre de luz en el sufismo iranio. Madrid, Ediciones Siruela, 2000, p. 111. 


\section{PALABRAS COMO ÁNGELES}

Sabemos que la traducción castellana del término griego «ángel» es la de mensajero, de donde también deriva la palabra «evangelio», si bien esta última posee el significado preciso de «buena nueva». Atendiendo a esta etimología, el ángel sería aquello que pone en comunicación la dimensión trascendente de la realidad con el mundo de las apariencias, es decir, el puente entre estos planos diferentes de existencia. Los ángeles cumplen -según el ya mencionado psicólogo arquetípico James Hillman- una función muy similar a la desempeñada por la palabra, dado que esta también es portadora de mensajes. No deja de ser significativo que la logofobia - es decir, el miedo a las grandes palabras como ser, amor, Dios, libertad, etcétera- manifestada por la corriente nominalista de la filosofía que se ha apoderado del panorama del pensamiento occidental durante los últimos siglos, discurra pareja a la desaparición de los ángeles de nuestro paisaje filosófico, religioso y psicológico, desterrados a lo más profundo de la mente como entidades ridículas y supeditadas a múltiples supersticiones. Sin embargo, al relegar a la trastienda psíquica a este tipo de entidades lo único que conseguimos es, paradójicamente, mutilar nuestra propia totalidad como seres humanos, cercenar facetas de nuestro equipamiento interior que resultan imprescindibles para el equilibrio psíquico.

Por ese motivo, escribe Antonio Betancor, prologuista del libro seminal de James Hillman Re-imaginar la psicología: «El ángel es anunciador del cielo, el revelador de su presencia en la tierra (el "hermeneuta del silencio divino" de los neoplatónicos), la llama de la conciencia que rescata las imágenes del alma de su cautiverio en los literalismos de la lógica, de la experiencia, y, si es preciso, de la fe. El ángel es el instaurador de un diálogo que no puede acontecer en su ausencia (¿quién puede hablar con un dios, una tierra, o un corazón que no tienen rostro?) [...] El ángel es... el aliento imaginal que mueve a los desconcertantes dioses de nuestras mitologías, y que inspira a filósofos, alquimistas, caballeros errantes y poetas, y es también, cómo no, el psicólogo en cada uno de nosotros que -llamado o no- restituye a la apariencia su profundidad, su elocuencia y su poder. Si, como afirma James Hillman, el anhelo esencial del alma es transparentarse, hacerse presente a sí misma, tal vez el secreto más recóndito de ésta - el secreto que une al hombre con el ángel de su epíteto posesivo y con la inaccesible divinidad- sea la transparentación definitiva, el paradójico encaje en el alma de lo visible y lo invisible en una metáfora continua, sin principio ni fin, que los orientales llaman iluminación $[\ldots] \gg .^{5}$

En ese sentido, parafraseando el título del mencionado libro de Hillman, debemos reimaginar no sólo la psicología, sino también las palabras, concibiendo a estas como presencias autónomas o huéspedes que nos habitan. Y, por su parte, prosigue diciendo Hillman:

5 James Hillman. Re-imaginar la psicología, Madrid: Ediciones Siruela, 1999, p. 22. 
«Nuestra ansiedad semántica nos ha hecho olvidar que también las palabras arden y se hacen carne cuando hablamos. Es necesaria una nueva angelología de las palabras para que podamos recuperar la fe en ellas. Sin la inherencia del ángel en la palabra -y «ángel» significa originalmente "emisario", "mensajero"-, ¿cómo vamos a expresar otra cosa que no sean opiniones personales, cosas elaboradas en nuestra mente subjetiva? ¿Cómo transmitir de una psique a otra algo de valor y con alma - una conversación, una carta, un libro-, si no hay significados arquetípicos en las profundidades de nuestras palabras?» ${ }^{6}$

Abundando, desde el punto de vista del sufismo, en el simbolismo que vincula a ángel y palabra, añadiremos que el dominio de experiencia en el que la función de los ángeles parece más íntimamente ligada al devenir de los seres humanos es la ciencia de las letras ('ilm al-hurūf). Según esta ciencia, que es un saber fundamental entre los santos musulmanes, la creación del cosmos tiene lugar a partir de las veintiocho letras del alifato combinadas entre sí en orden de complejidad creciente. Estas letras primordiales son consideradas ángeles en sí mismas. Es en ese sentido que Ibn 'Arabī declara que las letras del alifato son una comunidad de seres vivientes. De ese modo, si los ángeles también son palabras (verbos divinos, como los define Sohravardī), el conocimiento esotérico del lenguaje dará acceso al conocimiento esencial de los ángeles. Según el gran especialista en magia y esoterismo, el magrebí Aḥmad al-Būnī (s. xiii), cada aleya coránica es un ángel y cada palabra de la que remite a un ángel, el cual constituye su sentido oculto.

La anterior afirmación evoca la experiencia que tuvo Ibn 'Arabī durante su infancia, en la que habiendo caído en coma debido a una grave enfermedad, alcanza una visión en la que se ve acosado por un grupo de seres horrendos, hasta que de pronto son derrotados por una figura luminosa, de espectacular belleza, que exhalaba un poderoso perfume. Al preguntarle quién era, aquel ser le respondió que era la azora $Y \bar{a}-s \bar{n}$. Al despertar del coma, vio que su padre terminaba de recitar, en la cabecera de su lecho, dicha azora.

En otro orden de cosas, en ocasiones, los sufies sumergidos en trance profieren palabras y frases en lenguas desconocidas, y la enunciación de estas glosolalias se denomina (suryāniyya), un término que no se corresponde con el idioma arameo, tal como designa ordinariamente, sino con la lengua de los ángeles, el cual no es un idioma particular utilizado por estos, sino que designa el efecto de su presencia - dado que los ángeles son en sí mismos palabras-en el alma de los extáticos. ${ }^{7} \mathrm{Al}$ afirmar que los ángeles son palabras (así como las palabras son ángeles), debemos recordar que Gabriel, por ejemplo, es la palabra que dimana del divino Aliento del Misericordioso.

6 Ibid., pp. 69-70.

7 Pierre Lory, «Les anges dans l'islam». París, Connaissance des religions, 2004, pp.155-166. https://halshs. archives-ouvertes.fr/halshs-00323707 
El idioma de los ángeles también es sinónimo del lenguaje de los pájaros, criaturas estas con las que se simboliza, sobre todo en el ámbito del sufismo, a los ángeles. El Corán menciona a los pájaros en distintas ocasiones: «Sujetamos, junto con David, las montañas y las aves para que Le glorificaran» (21:79) «Y los pájaros en bandadas, todo vuelve a Él» (38:18-19). Nos informa también el Corán que Salomón fue instruido en el lenguaje de los pájaros y, por ese motivo, colmado de todo bien, siendo esta una ciencia heredada de su padre David. Por otro lado, se dice que el ejército de Salomón está constituido por seres humanos, ğinn y pájaros. De ese ejército formaba parte la abubilla, que le trajo noticias de la reina de Saba y fue devuelta a ella con un mensaje de parte de Salomón (27:15-17). Guando, en la leyenda nórdica, Sigfrido vence al dragón, entiende de inmediato el lenguaje de estos seres alados. La victoria sobre el dragón aporta la inmortalidad, la cual según el especialista en simbología René Guénon representa la comunicación con los estados superiores de la existencia, siendo los ángeles -y, por ende, los pájaros- la representación de dichos estados superiores de conciencia.

En definitiva, entender el lenguaje de los pájaros equivale a comprender el lenguaje secreto que habla cada ser por el mismo hecho de existir. Implica estar en posesión de la clave de los símbolos, y este privilegio se pone aquí en relación con el estado del alma preexistente a su caída en este mundo. «El lenguaje de los pájaros» es también el título de la célebre epopeya mística de la que es autor el persa Farīd al-Dīn 'Atțār (siglo xii) y que encuentra su desenlace en el símbolo del Sīmorg, un ave ancestral, el rey de las aves, que es el sumatorio de todos los pájaros que parten en su búsqueda. El tema de la abubilla mensajera será retomado en esta epopeya persa, erigiéndose en guía del resto de las aves en su viaje en pos del Sīmorg por haber servido a Salomón y estar en posesión de los secretos divinos. El papel de la abubilla como mensajera del mundo invisible no hace sino reforzar la identificación de pájaro, ángel y palabra divina.

Siendo David cantor y autor de los Salmos, es lógico relacionar el lenguaje de los pájaros con la poesía, tal como hace René Guénon en el artículo en el que aborda este tema. Y no olvidemos que el magnífico Cantar de los Cantares, atribuido a Salomón, que a tenor de lo dicho hasta el momento es una preclara muestra de poesía mística que ha dado lugar a innumerables comentarios a lo largo de la historia. Según Guénon, la expresión «lenguaje de los pájaros», o «lengua angélica», tiene su reflejo en el mundo humano en el lenguaje ritmado (que no rimado), pues es el dominio de las aplicaciones de la ciencia del ritmo escribe- el que puede ponernos en comunicación con las realidades superiores. Una tradición islámica - apunta de nuevo Guénon- señala que Adán en el Paraíso hablaba en verso, que es precisamente la lengua siríaca o suryāniyya, cuando la poesía tenía un genuino carácter sagrado que ha ido perdiendo, tal vez, con el paso del tiempo, aunque nunca completamente, a nuestro modesto entender. Todos los libros sagrados están originalmente escritos en dicho lenguaje ritmado. La poesía tenía el tratamiento en la antigüedad de lengua de los dioses, 
los cuales en numerosas tradiciones también son equiparables a los ángeles. En latín -sigue ilustrándonos René Guénon-, los versos se llamaban carmina, siendo la poesía carmen, una designación vinculada a la palabra sánscrita karma, pues era ese lenguaje ritmado el utilizado en el cumplimiento de los ritos, de igual modo que debemos traducir en este contexto la palabra karma como «acción ritual». Los poetas, los llamados vates, eran los intérpretes de la palabra divina, un sentido que permanece de algún modo presente en la palabra vaticinar, o adivinar el futuro, aunque la función de la adivinación es considerada una degradación de dicho lenguaje original.

Esta lengua original, este lenguaje de los pájaros, es el que permite, según la tradición bíblica, que Adán asigne nombre a cada cosa y también el que le lleva a entablar un fructífero diálogo con todo lo que le rodea, ya sea mineral, vegetal o animal. La nostalgia del Edén - escribe el poeta José Ángel Valente- es el deseo de reconstruir ese lenguaje primordial en la situación de no-dualidad del paraíso, en el que las palabras eran cosas y las cosas palabras.

\section{DIFERENTES PLANOS DE EXISTENGIA}

Las tradiciones proféticas y las enseñanzas cosmológicas islámicas, así como Ibn 'Arabī en Las iluminaciones de La Meca, señalan que los ángeles son creados a partir de la luz, los seres humanos del agua y la tierra, y los ğinn (es decir, los genios) del fuego. Escribe también el gran maestro que el ser humano está compuesto de espíritu, alma y cuerpo, o, expresado en términos coránicos, de luz, fuego y barro. El espíritu es una substancia luminosa y diáfana, muy similar a los ángeles, y por ello cabe afirmar que los seres humanos portan en sí mismos una naturaleza angélica. El alma, por su parte, está ubicada entre la luz y la oscuridad, entre espíritu y cuerpo, y este es el dominio que corresponde a los ğinn. Todo ello nos ayuda a entender por qué el Profeta señaló que Saytán - que según la angelología islámica no es un ángel caído sino un ğinn maligno- también habita en el interior de cada uno de nosotros. El ser humano, en tanto que compendio del cosmos visible e invisible, entraña dentro de sí todas las posibilidades de existencia. Por ese motivo, los seres humanos no pueden llamarse realmente tales a menos que despierten a su propia naturaleza angélica -el luminoso aliento divino que fue insuflado en su forma de arcilla tras ser amasada y modelada por el mismo Dios- y que también, como dijo el Profeta, conviertan al islam a su Saytán personal. Por supuesto, cuando se habla de convertir al islam, no nos referimos tanto a una tradición religiosa formal como a la pacificación del alma, tal como expresa también el Corán: «Oh, alma pacificada, regresa a tu Señor» (89:27-28). Teniendo en cuenta que la palabra «islam» significa «paz», no es dificil relacionar la pacificación del alma con su conversión a ese islam ubicado más allá de moldes históricos y dogmáticos. 
Estos tres tipos de criaturas -ángeles, ğinn y humanos- habitan en los tres planos principales de conciencia y de existencia en que la tradición sufí subdivide el cosmos visible e invisible, a saber: el plano espiritual, el imaginal y el sensorial, correspondientes a lo que se conoce en árabe como ğabarūt, malakūt y mulk, respectivamente. El ğabarūt es el plano existencial

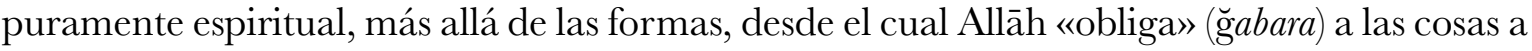
advenir a la existencia. Por ese motivo, también recibe la denominación coránica de «mundo de la orden», esto es, de la orden divina que obliga a ser a las entidades que deben ingresar en la corriente del devenir. Este es el plano en el que habitan Ğibrīl (Gabriel) y otros arcángeles. De hecho, ambas palabras, Ğibrīl y ğabarūt, tienen la misma raíz en árabe.

El «mundo de la orden» se opone al «mundo de la creación», formado este último por el mundo de los ángeles (malakūt) -también llamado mundo intermedio o reino imaginal- $\mathrm{y}$ el ámbito del mulk, donde habitan los seres humanos y el resto de los seres manifestados. La etimología de las palabras mulk y malakūt responden a la raíz trilítera $m-l-k$, que denota los sentidos de poder, reino o gobierno (de ahí también el término árabe malik, rey). La acepción de «poder» corresponde a la función de los ángeles menores en el conjunto de la creación de cumplir, sin dilación y en completa conformidad con la orden divina, lo que les ha sido encomendado por el Creador de todas las cosas. Asimismo, malak también significa «mensajero», «ayudante», «enviado», «superintendente»y «poderoso».

Existen, según el islam, distintas categorías de ángeles. No obstante, a diferencia de la angelología cristiana, expuesta principalmente por Pseudo-Dionisio Areopagita en su obra Las jerarquías celestiales, donde subdivide en triadas - a imagen de la trinidad divina- los distintos órdenes de ángeles (es decir, serafines, querubines y tronos; virtudes, dominaciones y potestades; principados, arcángeles y ángeles), la angelología islámica se basa principalmente en las menciones que efectúan el Corán y los hadices a este respecto. Entre las principales categorías de seres angélicos el Libro revelado menciona especialmente la de los «próximos» o «allegados» (muqarrabūn): «El Ungido no tendrá a menos ser siervo de Allāh, ni tampoco los ángeles allegados» (4:172). No olvidemos que Ibn 'Arabī también denomina de esta peculiar manera a la categoría más alta de los amigos de Dios.

En términos generales, la angelología islámica señala que, además de entidades espirituales sutiles de naturaleza lumínica, los ángeles carecen de voluntad propia y de necesidades biológicas: no necesitan comer ni dormir y, por tanto, tampoco soñar, y de ahí precisamente el título de nuestro artículo. El Corán abunda en menciones de su presencia y de sus múltiples actividades. De hecho, el texto sagrado los menciona en ochenta y ocho ocasiones. Las fuentes tradicionales los describen como seres de belleza sobrecogedora y también señalan que su número es desconocido; sólo conoce dicha cifra quien los ha creado. Sea como fuere, los ángeles ejemplifican las cualidades de perfección y obediencia, puesto que nunca flaquean en 
su glorificación y adoración a Dios y no albergan otro deseo sino el de servirle y obedecerle sin descanso, día y noche. Jamás se distraen de su cometido, siendo su único alimento la glorificación. Tampoco conocen -nos comenta Ibn 'Arabī- las prohibiciones. Y es por eso que sigue señalando el Corán: «No desobedecen a Dios en lo que Él les ordena» (66:6). Y respecto a esta adoración intrínseca recoge el Libro revelado: «Le glorifican, incansables, noche y día» (41:38); y también: «Suyos son quienes están en los cielos y en la tierra. Y quienes están junto a Él no se consideran demasiado elevados para servirle, ni se cansan de ello. Glorifican noche y día sin cesar» (21:19-20).

El Corán también señala: «Por temor a Él, el trueno celebra Sus alabanzas, y los ángeles también» (13:13). Alaban sin cesar a Dios quienes se congregan alrededor del Trono divino y los que lo portan: «Los que llevan el Trono y los que están a su alrededor celebran las alabanzas de su Señor, creen en Él y Le piden que perdone a los creyentes» (40:7). De ese modo, una de las principales funciones de los ángeles es interceder por los seres humanos. El Corán insiste en otro lugar en esta labor de intercesión: «Casi se hienden los cielos allí arriba al celebrar los ángeles las alabanzas de su Señor y pedir Su perdón en favor de los que están en la tierra. ¿ंNo es Allāh el Indulgente, el Misericordioso?» (42:5).

Nos advierte el texto coránico que el número de sus alas es variable. Algunos tienen dos, algunos tres y otros cuatro [se sobrentiende que pares] (35:1). Las alas angélicas son interpretadas en el sentido de que los ángeles se hallan en constante actividad. Cuando mueven sus alas, cada movimiento les lleva a una nueva situación. También se afirma que ese número tiene que ver con la rapidez en cumplir la misión que tienen encomendada.

Según se desprende de la lectura tanto de los textos sagrados como de los sabios sufíes, parecen existir ángeles de naturaleza más permanente, por así decirlo, y ángeles que emergen debido a las acciones de los seres humanos. Por ejemplo, se afirma que, cuando estos recuerdan a Dios o cuando llevan a cabo buenas acciones, dichos actos engendran ángeles bellísimos. Luego tenemos los arcángeles, de los cuales Ğibrīl, Mīkāōil e Israfil son los más importantes y los guardianes de toda forma de vida. Ğibrīl es el depositario de la Revelación que lleva la vivificación espiritual a las almas y los corazones; a Mīkāîl le ha sido confiada, entre otros cometidos, la lluvia mediante la cual las plantas, los animales y el suelo son nutridos por la vida; mientras que Israfil es el depositario de la trompeta cuyo toque convocará a muertos y vivos al llegar el Día del Juicio.

No hay lugar en el cosmos que no esté custodiado por ángeles. Un ángel acompaña a cada gota de lluvia, y se requieren siete de ellos para que crezca una sola hoja de un árbol. Además, según explica el místico persa Sohravardī, cada especie presente en nuestro mundo cuenta con su propio ángel. Ibn 'Arabī aborda en distintos lugares el simbolismo de las funciones angélicas y establece correspondencias con los doce signos del zodiaco. Por ejemplo, además 
de comentar que es de naturaleza seca y caliente, el signo de Aries está regido por un ángel que controla la creación de las cualidades y los accidentes; Cáncer es frío y húmedo, y su ángel rige la creación del mundo; Géminis es caliente y húmedo, y su ángel posee en particular la clave de la creación de los metales, etcétera. ${ }^{8}$

En el texto titulado en castellano La alquimia de la felicidad, el cual conforma el capítulo 167 de Las iluminaciones de La Meca, Ibn 'Arabī nos describe el Viaje Nocturno y la Ascensión través de las esferas celestiales y, además de otras consideraciones, escribe respecto a la génesis de los metales y su relación con cada ángel planetario: «En ese preciso instante (en que aparece la forma metálica), la toma a su cargo la "entidad espiritual" de uno de los siete planetas móviles, esa entidad es uno de los ángeles de ese cielo. Ese ángel se mueve conjuntamente con el planeta sometido a su circunvalación, siendo Dios quien le dirige hacia una meta asignada por su Creador. Y el objetivo es conservar intacta la fuente propia de esa sustancia metálica. Es así que este ángel astral que tiene por generoso corcel ese planeta, toma a su cargo la forma del hierro y efectúa su revolución en el séptimo cielo, contado desde nuestro planeta. De la misma manera el estaño, como cualquier otro metal, es tomado a cargo por el ángel que tiene por corcel el planeta (correspondiente a ese metal) y gira en su cielo propio y en la órbita particular, asignada y dirigida por su Señor». ${ }^{9}$

También hay un ángel -sostiene un hadiz- que cuida del desarrollo del embrión durante los primeros cuarenta días, que pasa a ser relevado por otro que cuida de él durante un periodo similar y aun otro durante otros cuarenta días, hasta que es enviado un ángel que insufla el espíritu en el ser que va a nacer, anotando nuestra riqueza, la longitud de nuestra vida, nuestras acciones y si seremos miserables o felices. En el texto recién citado, el gran maestro andalusí también expone la relación que mantiene cada ángel planetario con el desarrollo del embrión en el seno materno. Así pues, el ángel del cielo donde mora Adán, regido por la luna, está encargado de velar durante el séptimo mes que sigue a la caída del semen dentro del útero. Al ángel guardián que habita en el cielo de Jesús vela por el desarrollo del feto durante el sexto mes. En el cielo de José, presidido por el planeta Venus, se ubica el ángel que preside la transformación en la matriz de la gota de esperma durante el quinto del mes, etcétera.

Por su parte, los ángeles custodios - de los cuales, a diferencia del cristianismo, en el islam existe un elevado número- velan por todos los seres humanos en cualquier tipo de situación y circunstancia, tanto si están despiertos como dormidos. Por eso, leemos en el Corán: «Da lo mismo que uno de vosotros diga algo en secreto o lo divulgue, se esconda de noche o se

8 Titus Burckhart, Clave espiritual de la astrología musulmana según Muhyidín Ibn Arabi. Palma de Mallorca, José Olañeta, 1984, p. 23.

9 Ibn al-Arabi, Textos espirituales. Madrid, Editorial SUFI, 2004, p. 20. 
muestre de día. Tiene, por delante y por detrás, pegados a él, que le custodian por orden de Allāh» (13:10-11). Y también señala: «Él es quien domina a Sus siervos. Envía sobre vosotros a custodios» $(6: 61)$.

En el momento de la muerte es enviado un ángel, llamado 'Azrā’il, con el encargo de recoger el alma del difunto. A este respecto nos dice el Corán: «El ángel de la muerte, encargado de vosotros, os llamará y luego seréis devueltos a vuestro Señor» (32:11). Una tradición profética mantiene que, al ser depositados en la tumba, los difuntos reciben la visita de dos ángeles, llamados Nakīr y Munkar, quienes les interrogan sobre sus actividades en este mundo. A lo largo de la vida de cada persona, hay dos ángeles encargados de anotar cómo se comporta, y los rollos de papel que escriben se convierten en documentos decisivos en el Día del Juicio.

También están los guardianes del Jardín y el Fuego, respectivamente. El principal de los ángeles del Jardín se denomina Riḍwān (39:73). Por su parte, el jefe de los guardianes del infierno se llama Mālik y tiene a su cargo diecinueve ángeles que son los que gobiernan al resto de los ángeles que vigilan la Gehena (el infierno) (40:49-50; 66:6; 74:27-31). El último rango de los ángeles son los generados a partir de los actos y los alientos de los adoradores. Así, por ejemplo, los ángeles del $\underline{d} i k r$ viajan a la busca de las reuniones en las que se recuerda a Dios.

Mención aparte merece el grado angélico de los llamados karubiyyūn (querubines), los más próximos a Allāh. Ellos son los ángeles más importantes, ya que la manifestación del cosmos se inicia con ellos. Son, en cierto modo, y como explicaremos más adelante, el tejido de que está constituida la creación. La actividad exclusiva de los karubiyyūn consiste en adorar y contemplar a Dios. Por ese motivo, son los únicos seres de la creación que pueden verlo directamente sin ser pulverizados por las luces que emanan de Su Faz. Estos ángeles se hallan tan arrebatados por el amor hacia Allāh que ni siquiera se percatan de que el cosmos ha sido creado. Uno de estos ángeles arrebatados es el designado por Dios para hacerse cargo del conocimiento de la creación. Es el llamado Primer Intelecto, Cálamo, Espíritu. La primera creación de Allāh - señala Ibn 'Arabī- son estos espíritus angélicos embargados por el amor hacia la majestad divina.

La luz aporta el ingrediente esencial de la creación y es también el símbolo más reconocible de la divinidad. A pesar de que los hadices declaren que Dios está envuelto por setenta velos de oscuridad y de luz, también está escrito en el Corán que «Allāh es la luz de los cielos y la tierra» y «Luz sobre luz» (24:35). Al proclamar que los ángeles han sido creados a partir de la luz, que poseen cuerpos luminosos y que se hallan presentes por doquier en el cosmos, se infiere que constituyen un componente esencial de la existencia, conformando la estructura íntima del universo y de la vida. La luz - escribía Albert Einstein- es la sombra de Dios. 
Los ángeles no actúan tan sólo como mensajeros, sino que el mundo es creado por y con los ángeles. Ello supone que el cosmos está impregnado de luz, vida y conciencia. Dados el carácter luminoso y la ubicuidad de los ángeles en los procesos de la creación, podemos considerarlos como el esqueleto de luz - es decir, la estructura interna de la realidad- que sustenta tanto al universo como al ser humano.

\section{EL SER HUMANO GOMO MAESTRO DE LOS ÁNGELES}

Acabamos de sugerir que la figura del ángel constituye un contrapunto espiritual para el ser humano que aspira a la perfección y que presupone su completitud como ser integral, asentado con los pies en la tierra, pero con la cabeza puesta en el cielo, si se nos permite la expresión. Sin embargo, de la mano de Ibn 'Arabī, vamos ahora a enfocar la cuestión de un modo diferente e incluso opuesto, porque no podemos pasar por alto que, siguiendo el mensaje coránico y también las enseñanzas del gran maestro andalusí, el ser humano -se sobreentiende que el ser humano perfecto o universal o lo que él llama también el Gran Hombre (al-insān al-kabīr), equiparable al conjunto del cosmos- también es descrito como maestro de los ángeles, dado que Allāh lo ha encumbrado por encima de las demás criaturas, incluidos los ángeles, pues estos desconocen la totalidad de los nombres de Dios, que sólo Adán conoce al haber sido creado con ambas manos divinas.

Tampoco podemos obviar que la primera mención que tanto el Génesis como el Corán hace de los ángeles ocurre cuando se aborda la creación del ser humano; de ahí que, para las tradiciones del Libro, ambos sean realidades indisociables. El ser humano constituye la gran revelación para los ángeles, el factor sorpresa de la creación, porque este se les muestra como algo que está más allá de su comprensión y su predictibilidad.

Los ángeles no disfrutan de la universalidad de Adán y tampoco entienden los nombres divinos con los que este ha sido favorecido y mediante los cuales adora a Allāh de modos desconocidos e inaccesibles tanto para los ángeles como para otros habitantes del cosmos visible e invisible. Por eso, cuando Dios les ordena que se postren ante esa extraña y paradójica criatura que es el ser humano, los ángeles se sienten desbordados por la sorpresa. Lo único que aciertan a farfullar es: «¿Vas a poner en la tierra a quien la corrompa y derrame sangre?» $(2: 30)$.

Siguiendo con la descripción akbarí, tras habérseles ordenado postrarse ante el recién creado Adán, los ángeles pasan a ser descritos como las facultades de este ser que, en palabras del Šayh al-Akbar, es la forma del universo y, por eso, los sufíes lo designan con la expresión técnica de «Gran Hombre». Los ángeles - apunta Ibn 'Arabī- son, para este Gran Hombre, 
lo que las facultades espirituales, intelectuales y sensoriales son para cada ser humano particular. Recordemos que las facultades humanas abarcan desde los sentidos materiales - es decir, la capacidad de visión, audición, etcétera- hasta las potencias puramente anímicas como voluntad, imaginación, memoria o entendimiento.

La explicación reside en que los ángeles son, por un lado, potencias circunscritas a desempeñar una función concreta en el cosmos y, en ese sentido, se parecen al cometido exclusivo que, en el ser humano, cumple cada uno de nuestros sentidos, así como nuestras facultades internas. Por otro lado, los ángeles no son una realidad completa. Si bien su condición es más pura que la del ser humano desde el punto de vista de su servicio y adoración a Dios, su naturaleza también es más restringida y especializada, es decir, pueden desempeñar cometidos específicos, pero no pueden conjuntarlos todos de igual modo que lo hace el ser humano, quien es heredero del conjunto de los nombres divinos, tanto los de rigor como los de misericordia. Los ángeles no poseen, a diferencia del ser humano, la libertad, aparente al menos, de desobedecer. Con frecuencia se ha suscitado entre los teólogos la cuestión de quién ocupa un lugar más prominente en la creación, si ángeles o seres humanos. La mayoría de autores se decanta por estos últimos. Debemos tener en cuenta, no obstante, que no estamos refiriéndonos al común de los hombres y mujeres, sino exclusivamente al ser humano perfecto (al-insān al-kāmil).

$\mathrm{Al}$ principio de su texto quintaesencial Los engarces de la sabiduría, Ibn 'Arabī explica que, cuando Dios - lo Real- deseó contemplarse a sí mismo en un objeto todo-inclusivo, capaz de mostrarle su propio misterio, porque -señala el texto- «ver una cosa en y por sí misma no es lo mismo que verla en otro como, por ejemplo, un espejo». De ese modo -y citamos ahora literalmente el texto de 'Ibn 'Arabī: «Lo Real otorgó existencia a la totalidad del Cosmos [al principio] como una cosa indiferenciada carente de espíritu, de manera que era como un espejo sin pulir [...] la Orden [divina] requería [por su misma naturaleza] la cualidad reflexiva del espejo del cosmos, y Adán era el mismo principio de reflexión de ese espejo y el espíritu de esa forma, mientras que los ángeles sólo eran ciertas facultades de esa forma que era la forma del Cosmos, llamada, según la terminología de los Compañeros, el Gran Hombre. En relación con él, los ángeles son comparables a las facultades físicas y psicológicas en la configuración humana. Cada una de estas facultades o poderes cósmicos está velado [respecto al conocimiento de la totalidad] por su propio ser [estando limitado por su individualidad relativa], de manera que no puede conocer nada que la sobrepase $\left[\ldots . .{ }^{10}{ }^{10}\right.$

Esta percepción de la totalidad puede ser interpretada en el sentido de que se requiere un órgano integral de sabiduría -o, si se prefiere, la integración de todos nuestros instrumentos

10 Ibn al-Arabi, The Bezels of Wisdom (traducción e introducción de R.W.J. Austin), Nueva York, Paulist Press, 1980, p. 48. 
intelectuales y espirituales- para ir más allá de la comprensión intelectual meramente especulativa o del conocimiento proporcionado por las emociones y los sentidos: una auténtica síntesis de razón, corazón y órganos sensoriales, puesto que ninguno de ellos está, por sí solo, en condiciones de suministrarnos una imagen completa de la realidad.

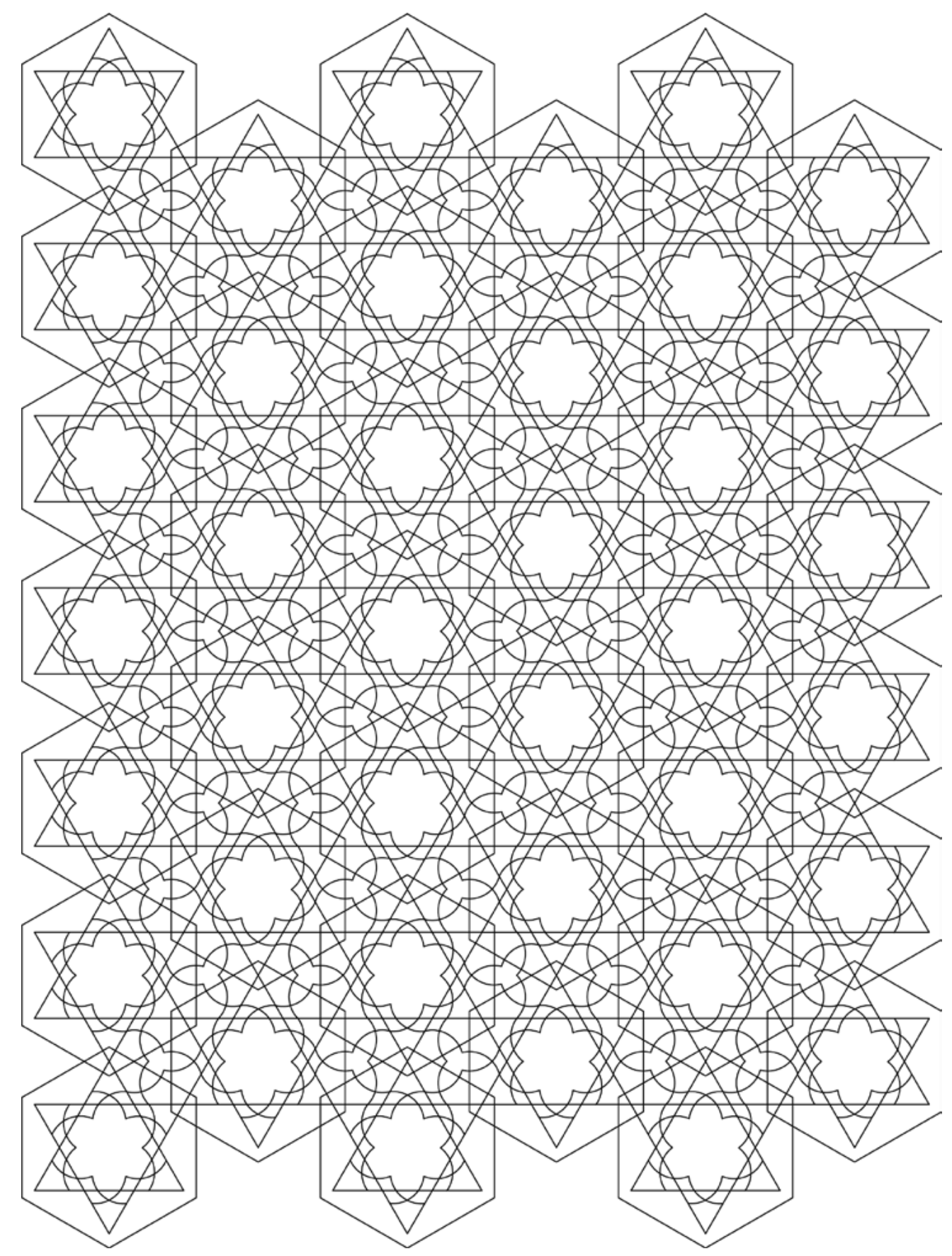

